\title{
MANDIBULOFACIAL DYSOSTOSIS IN AN AFRICAN INFANT
}

\author{
BY \\ SAMUEL WAYBURNE \\ From the Department of Paediatrics, Baragwanath Hospital and University of the Witwatersrand, Johannesburg
}

(RECEIVED FOR PUBLICATION NOVEMBER 20, 1952)

Under the title of 'mandibulofacial dysostosis' Franceschetti and Klein (1949) described a comparatively uncommon but easily recognizable condition, tending to appear in families and showing an irregular dominant mode of inheritance. Berry (1889) first recorded the condition in a mother and her daughter. Most of the descriptions have appeared in the Continental and American literature*. As far as can be ascertained this is the first description of the fully developed syndrome in an African Negro.

The salient features of this type of dysostosis are (1) palpebral fissures sloping downwards and laterally ('antimongoloid') with a coloboma in the outer portion of the lower lids and, more rarely, in the upper lids; (2) hypoplasia of the facial bones, especially the malar bones and the mandible; (3) malformation of the external ear and, occasionally, of the middle and inner ears; (4) macrostomia, high palate, abnormal position and malocclusion of the teeth; (5) blind fistulae situated between the angles of the mouth and the ears; (6) a tuft of hair extending towards the cheeks; (7) other associated anomalies such as facial clefts and further skeletal deformities.

\section{Case Report}

S.N., an African boy aged 5 weeks, was admitted to the Paediatric Department of Baragwanath Hospital on August 29, 1951. The main complaints were of difficulty in breathing since birth and loss of weight. Pregnancy and labour had been normal, and the mother denied any illness during gestation. The baby took the breast and also received complementary feeds of sweetened condensed milk. In spite of the breathing diffculty he had sucked well, but sleep had been erratic and poor. There was no history of diarrhoea or vomiting. The birth weight was unknown. There was one 4-year-old normal sibling. The mother was quite well, but the father had been completely deaf since childhood. The parents appeared to be of normal intelligence.

- The condition is often referred to as the Treacher-Collins syndrome (Collins, E. T. (1900), Trans. ophth. Soc., 20, 190).-ED.
Examination revealed a cold, cyanosed, extremely wasted, dehydrated baby, weighing $5 \frac{1}{4} \mathrm{lb}$., breathing with great difficulty and showing marked rib recession. A peculiar facies was immediately noted. The face was very narrow, the palpebral fissures sloped downwards and outwards, and there was a coloboma in the lateral part of each lower lid. The jaw was very small, while the mouth and tongue were large, the latter falling back into the pharynx and causing respiratory obstruction. The pinnae were markedly deformed and just anterior to the upper part of each was a small, blind fistula. The tympanic membranes were normal. There was a depression in the

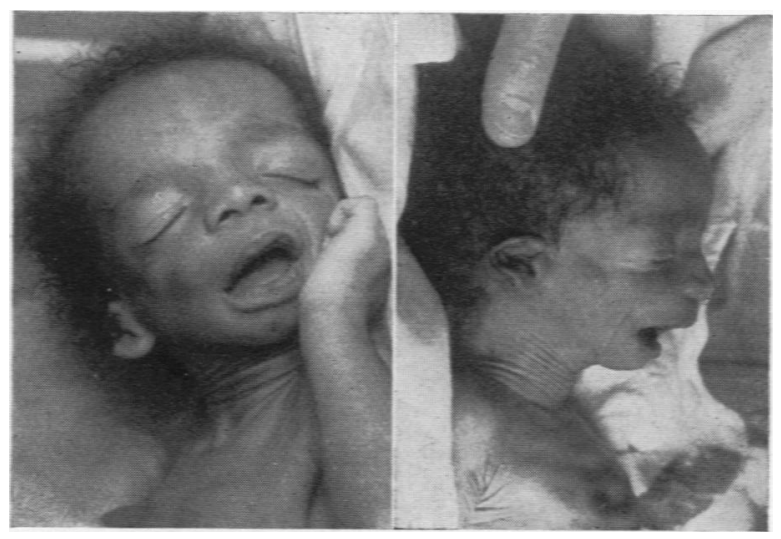

Fig. 1.

Fig. 2.

FiG. 1.-Macrostomia, downward and outward obliquity of the palpebral fissures, and deformity of the pinna.

Fig. 2.-Micrognathia: deformity of pinna with adjacent fistula; depression in region of malar bones with small tuft of hair.

region of each zygoma, from which grew a tuft of fine hair.

The baby was resuscitated by intravenous therapy, followed by nasal tube feeds and in three to four days was able to take the bottle. Great care had to be taken in positioning him, otherwise respiratory obstruction recurred.

Further investigation revealed normal ocular fundi and negative serological tests for syphilis. 


\section{Discussion}

The features shown by this baby are typical of the syndrome described by Franceschetti and Klein (1949). They stated that there was in their cases a disturbance of development and ossification of the facial bones dating from the end of the second month of gestation. They quoted numerous family histories of affected parents and children and some of their near relations including the families of six cases of their own. Several of the affected patients died in the first six months of life (Debusmann, 1940). The frequency of infantile mortality amongst the siblings and relatives of Franceschetti and Klein's patients was found to be very high.

It has also been found that there are sometimes associated anomalies such as atresia of the lacrimal duct and ectropion, complete atresia of the external auditory canal and inner ear deformities.

McEnery and Brennemann (1937) described a series of five cases with similar features, some being unilateral. They quoted as characteristic findings the presence of cleft lip or cleft palate, defective zygomatic arch, a sharp angular or downward depression of both lower lids, microphthalmos, deformity of one or both ears and a tendency to mental retardation. They gave an embryological description from the work of Blair and Brown (1938) stating that:

'Congenital deformities of the mouth and face are most frequently related to some abnormality of development or closure of the embryonal fissures, but there are many other types of deformities that do not have as definite a basis of origin.'

The latter authors give a photograph and description of a child with obvious manifestations of the syndrome and regard this particular child as suffering from an unclassified type of gross deformity that may be associated with cleft palate, deformity or absence of ears, deformity of the nose and microphthalmia.

Franceschetti and Klein divide their own and reported cases into complete, incomplete, abortive, unilateral and atypical forms, and stress the diagnostic importance of the slope of the eyes and coloboma of the lower lids. One of the patients discussed by them was a 3-year-old Negro girl described by Leopold, Mahoney and Price (1945). She showed an incomplete form of the syndrome, the chief features being the downward obliquity of the palpebral fissures with coloboma of the lower lids, although the ears were normal. The mother and maternal grandfather of this child showed downward obliquity of the palpebral fissures and all three of them showed bilateral absence of the zygomatic processes of the temporal bones. Three other members of the family were also reported as having been affected.

The only abnormality ascertained in the family history of our patient was the father's deafness. a condition present since his childhood. His external ears showed no deformity, but the tympani were sclerosed and retracted. His speech, however, was normal, indicating that his deafness was probably acquired. Full auditory examination was not carried out. No history of mental defect or congenital abnormality in any other member of the family was admitted. It should be noted that the illiterate parents of the child were so unobservant that apparently they had not noticed the facial anomalies.

Subsequent attempts to follow the child's development were unsuccessful, and it was reported that the infant succumbed at the age of 3 months, the cause of death being unknown.

\section{Summary}

A case of mandibulofacial dysostosis in a baby of pure African origin is presented. The child showed the typical obliquity of the eyes with coloboma of the lower lids, hypoplasia of the facial bones and mandible, macrostomia, blind fistulae anterior to the pinnae and tufts of hair over the region of the hypoplastic zygomatic arches.

The literature is reviewed and the aetiology discussed.

I wish to thank Dr. J. D. Allen, Medical Superintendent of Baragwanath Hospital, for permission to publish the data on this patient.

\section{REFERENCES}

Berry, G. A. (1889). Roy. Lond. opthal. Hosp. Rep., 12. 255 : quoted by Franceschetti and Klein.

Blair, V. P. and Brown, J. B. (1938). In Brennemann, J., Practice of Pediatrics, vol. 3, ch. 1. Hagerstown, Md.

Debusmann, -. (1940). Arch. Kinderheilk., 120, 133: quoted by Franceschetti and Klein

Franceschetti, A. and Klein, D. (1949). Acta ophthal Kbh, 27, 143 Leopold, I. H., Mahoney, J. F. and Price, M. L. (1945). Arch. ophthal. Chicago, 34,210 .

McEnery, E. T. and Brennemann, J. (1937). J. Pediat., II, 468. 